\title{
Rationales for and limitations of preferred solutions for multi-functionality problems in LCA: is increased consistency possible?
}

\author{
Nathan Pelletier • Fulvio Ardente • Miguel Brandão • \\ Camillo De Camillis • David Pennington
}

Received: 25 January 2014 / Accepted: 16 October 2014 / Published online: 11 November 2014

(C) Springer-Verlag Berlin Heidelberg 2014

\begin{abstract}
Purpose The ISO 14044 standard for life cycle assessment (LCA) provides the reference decision hierarchy for dealing with multi-functional processes. We observe that, in practice, the consistent implementation of this hierarchy by LCA practitioners and LCA guidance document developers may be limited. In an attempt to explain this observation, and to offer suggestions as to how consistency in LCA practice might be improved, we identify and compare the rationales for (and limitations of) different common approaches to solving multifunctionality problems in LCA.

Methods The different prevalent understandings of specific approaches for dealing with multi-functional processes were identified, and their respective rationales were analyzed. This takes into account identifying the implicit underlying assumptions regarding the nature and purpose of LCA that support each approach.

Results and discussion We identified what we believe to be three internally consistent but mutually exclusive schools of thought amongst LCA practitioners, which differ in subtle but important ways in terms of their understanding of the nature and purpose of LCA, and the multi-functionality solutions necessary to support them. These three divisions follow two demarcations. The first is between consequential and attributional data modeling approaches. The second is between adherence to a natural science-based approach (privileging physical allocation solutions) and a socioeconomic approach
\end{abstract}

Responsible editor: Rolf Frischknecht

N. Pelletier $(\bowtie) \cdot$ F. Ardente $\cdot$ C. De Camillis $\cdot$ D. Pennington European Commission, Joint Research Centre, Institute for Environment and Sustainability, Via E. Fermi 2749, 21027

Ispra, VA, Italy

e-mail: nathanpelletier@globalecologic.com

M. Brandão

Massey University, Palmerston North, New Zealand (favoring economic allocation solutions) in attributional data modeling.

Conclusions We conclude that the ISO 14044 multifunctionality hierarchy should explicitly differentiate between attributional and consequential data modeling applications. We question the feasibility and practical utility of system expansion (currently privileged in the ISO hierarchy) in attributional data modeling applications. We suggest that ISO 14044 should also make explicit its rationale for privileging natural science-based approaches to solving multifunctionality problems and to more clearly differentiate between natural science and social science-based approaches. We also call for the formulation of additional guidance for solving multi-functionality problems, in particular for justifying the use of lower-tier solutions from the ISO hierarchy when these are applied in LCA studies. We suggest that this additional guidance and clarity in ISO 14044 will contribute to increased consistency in LCA practice and also increase the potential for users of information from LCA studies to make informed decisions as to their relevance within the context of specific intended applications.

Keywords Attributional · Consequential · Economic allocation · ISO $14044 \cdot$ LCA $\cdot$ Multi-functionality $\cdot$ Physical allocation $\cdot$ System expansion

\section{Introduction}

Multi-functionality problems are commonly encountered in LCA studies. How such problems are resolved is a critical determinant of LCA study results. Multi-functionality problems may be solved in a variety of ways, depending on the goal and scope of a study and the specifics of a particular problem (Reap et al. 2008). Allocation is one common strategy for solving multi-functionality problems. According to the 
ISO 14044 standard for life cycle assessment (LCA) (ISO 2006a), allocation refers to "partitioning the input or output flows of a process or a product system between the product system under study and one or more other product systems." Other approaches attempt to avoid the need to allocate via process subdivision or by changing the system boundary of the study.

ISO 14044 (ISO 2006a), the international reference standard for LCA, provides the following decision hierarchy for use in studies wishing to claim ISO compliance:

"The study shall identify the processes shared with other product systems and deal with them according to the stepwise procedure presented below.

a) Step 1: Wherever possible, allocation should be avoided by

1) dividing the unit process to be allocated into two or more sub-processes and collecting the input and output data related to these sub-processes, or

2) expanding the product system to include the additional functions related to the co-products.

b) Step 2: Where allocation cannot be avoided, the inputs and outputs of the system should be partitioned between its different products or functions in a way that reflects the underlying physical relationships between them; i.e. they should reflect the way in which the inputs and outputs are changed by quantitative changes in the products or functions delivered by the system.

c) Step 3: Where physical relationship alone cannot be established or used as the basis for allocation, the inputs should be allocated between the products and functions in a way that reflects other relationships between them. For example, input and output data might be allocated between coproducts in proportion to the economic value of the products."

As evidence that these ISO recommendations are not easy to interpret nor straightforward to implement in practice, this hierarchy is not reflected in more recently developed guidelines for studies based on life cycle approaches-see, for example, the respective multi-functionality hierarchies of the Greenhouse Gas (GHG) Protocol (WRI/WBCSD 2011) and BP X30-323 (ADEME 2010). Such inconsistency between standards ostensibly building on ISO14044 raises questions as to its current effectiveness as a general standard for LCA (Weidema 2014). As frequent readers and reviewers of LCA literature, we similarly note considerable heterogeneity in how different practitioners solve comparable multi-functionality problems in LCA. We also observe that justifications for multi-functionality solutions in published LCA studies are often not provided (such justification is increasingly required in emerging standards, for example, the ETSI (2011) 103199 technical specification for LCA of ICT equipment, networks and services, and the ENVI-Food Protocol). It is hence often difficult to determine the basis of this seeming inconsistency.

Unfortunately, the ISO 14044 standard does not provide an accompanying supporting rationale for its three-tier hierarchy and detailed, broadly accepted guidance with clear illustrations on how to move along this hierarchy is not available. Moreover, the lack of definition of key terms (such as "system expansion") creates space for alternative interpretations of the nature and relevance of each tier. Another possible cause of confusion is the use of the term "shall" (which, ostensibly, indicates that a requirement must be followed) in relation to application of the hierarchy alongside the use of the terms "should" and "wherever possible" in relation to actual application of a given tier. Finally, no distinction is made between different life cycle inventory data modeling approaches (i.e., attributional and consequential LCA), which may actually be better served by distinct multi-functionality hierarchies.

Establishing a systematic and principled basis for identifying the most appropriate solution for dealing with multifunctionality problems in a given context is highly desirable in order to ensure that:

- the choice can be defended based on a clear rationale (for example, with reference to a specific form of causality).

- the choice results in an internally consistent, logically structured, and maximally representative model of the product system and associated environmental burdens.

- the choice is consistent with the aims and intended applications of the analysis.

- comparable study results are produced across similar studies.

In the absence of such a principled and systematic basis, LCA guidelines and studies of similar systems undertaken by different researchers according to their own approaches/ beliefs for solving multi-functionality problems are likely to produce divergent results. This may undermine the acceptance of LCA and its decision support potential (Heijungs and Guinée 2007; Reap et al. 2008).

This paper proceeds from the position that interpretation and systematic application of a multi-functionality decision hierarchy for LCA, with supporting criteria, is only possible on the basis of internally consistent and mutually reinforcing definitions of:

- the nature of LCA

- the purpose of LCA

- the conditions necessary for the product system models constructed in LCA studies to respect the (defined) nature and support the (defined) purpose of LCA - including solutions to solve process multi-functionality 
Without clear articulation and reference to these fundamentals, we maintain that it will not be possible to coherently defend a general approach to resolving multi-functionality problems (for example, the current ISO 14044 hierarchy) nor specific applications. Achieving greater consistency between LCA studies will also remain elusive (Andrae and Andersen 2010).

The purpose of this paper is therefore to analyze the rationales for the predominant schools of thought with respect to preferred approaches to solving multi-functionality problems. These approaches are as follows: system expansion, physical allocation, and economic allocation (representing allocation based on "some other relationship"). We believe that these three options are generally (although not exhaustively) representative of current practice. Subdivision is not further considered in detail, as this is seemingly universally viewed as the preferred approach to avoiding allocation. We further make what we consider to be an essential distinction between attributional and consequential data modeling and the multifunctionality solutions that are respectively compatible with each. We subsequently propose multi-functionality hierarchies that are consistent with each of these three positions and conclude with a discussion of what our observations point toward as possible improvements for the current ISO 14044 multi-functionality decision hierarchy.

\section{Methods}

Relevant scientific peer-reviewed papers for this review were identified by searching for terms such as "allocation," "LCA," "multi-functionality," and "review" in some of the commonly used research search engines (e.g., Google Scholar, Scopus, ISI Web of Knowledge, ScienceDirect). On the basis of this literature review, as well as content from online exchanges in LCA fora such as the LCT forum of the European Commission's Joint Research Centre and the LCA mailing list administered by Pré Consultants, preferred approaches to dealing with multi-functional processes in LCA and their supporting rationales were identified along with the associated explicit or implied understandings of the nature and purpose of LCA. This included distinguishing between attributional and consequential data modeling approaches. We also identified and analyzed the key criticisms of each of these three approaches from the perspectives of the competing schools of thought. We subsequently derived a set of alternative versions of multifunctionality solution hierarchies that are respectively consistent with the rationales that underpin each approach and suggestions for potential future improvements of the ISO 14044 multi-functionality hierarchy.

For attributional and consequential data modeling approaches, we refer to definitions agreed in a recent workshop (UNEP/SETAC 2011):
"Attributional approach" (also called "accounting" or "descriptive" approach) "attempts to provide information on what portion of global burdens can be associated with a product (and its life cycle). In theory, if one were to conduct attributional LCAs of all final products, one would end up with the total observed environmental burdens worldwide. The systems analysed ideally contain processes that are actually directly linked by (physical, energy, and service) flows to the unit process that supplies the functional unit or reference flow."

"Consequential approach" (also called change-oriented approach) attempts "to provide information on the environmental burdens that occur, directly or indirectly, as a consequence of a decision (usually represented by changes in demand for a product). In theory, the systems analysed in these LCAs are made up only of processes that are actually affected by the decision, that is, that change their output due to a signal they receive from a cause-and-effect chain whose origin is a particular decision."

\section{Results and discussion}

We identified what we believe to be three internally consistent but mutually exclusive schools of thought amongst LCA practitioners, which differ in subtle but important ways in terms of their understanding of the nature and purpose of LCA and the multi-functionality solutions necessary to support them. These three divisions follow two demarcations. The first is between consequential and attributional data modeling approaches and the meaning/feasibility of system expansion in each. The second is between adherence to a natural science-based approach (privileging physical allocation solutions) and a socioeconomic approach (favoring economic allocation solutions) in attributional data modeling.

\subsection{System expansion (and substitution): approaches} and supporting rationales

The first tier solution in the ISO 14044 multi-functionality hierarchy is to avoid allocation by either subdividing the process (subdivision) or by "expanding the product system to include the additional functions provided by the co-products." Alternative interpretations of the system expansion definition are possible. One option, and literal interpretation of ISO 14044, is that system expansion simply requires analysis and reporting at the level of all co-products, i.e., the system is modeled avoiding allocation (for example, as per the ETSI Annex 0.3 illustration for mobile phones that deliver voice, SMS, and internet browsing functions). However, if 
reporting impacts at the individual co-product level is desired, system expansion according to this definition may not be useful (Guinée et al. 2002; Wardenaar et al. 2012). This may be particularly the case when trying to attribute resource-use/ emissions to a specific product to reflect its current share of burdens using the attributional data modeling approach (see below).

Although not referred to in ISO 14044, some practitioners consider that system expansion is commensurate with substitution (for example, see Tillman et al. 1994; Ekvall and Weidema 2004; Lund et al. 2010). Substitution refers to identification and modeling of mono-functional processes external to the considered system, which yield products or functions that are equivalent to those of the co-products of the multi-functional process of interest. These are added to or subtracted from the system model in order to achieve a desired functional unit. Most commonly, these inventories are subtracted from the inventory of the original multifunctional process in order to isolate the remaining inventory attributable to the co-product of interest.

Repeated in a variety of publications (Ekvall and Tillman 1997; Finnveden and Lindfors 1998; Ekvall and Finnveden 2001), the argument regarding commensurability between system expansion and substitution may be traced back to Tillman et al. (1994), who suggested that the two approaches are "conceptually equivalent." The feasibility and meaningfulness of this approach may, however, depend on the data modeling approach adopted, i.e., attributional versus consequential modeling.

\subsubsection{System expansion + substitution in consequential data modeling}

Consequential LCA is a change-oriented, system-level data modeling approach that relies on system expansion + substitution to avoid multi-functionality problems. It is used to quantify the change in the life cycle burdens that will occur at the level of the economic system as a whole when one product is substituted by another as a result of a change in a production process. For example, when a change in a production process results in an increase of a specific co-product of interest in the market, a corresponding increase of the market availability of the other co-products will also occur. A commensurate decrease in the production of the marginal market equivalent of each co-product is assumed (substitution). The net environmental impacts of these changes are quantified (Weidema et al. 1999; Weidema 2000; Ekvall and Andrae 2006).

System expansion + substitution has sometimes been employed in the context of consequential modeling of biofuel feedstock supply chains (Kløverpris et al. 2008; Edwards et al. 2010; Brandão 2012). Here, for example, an increase in the production of a biofuel feedstock such as soybeans results in the availability of soy oil (for biodiesel production) as well as increased market availability of the co-product, soymeal, which is used as animal feed. Following a consequential data modeling approach, this increased availability of soymeal can be assumed to substitute production of the marginal market equivalent of soymeal (this could be, for example, rapeseed meal produced in a specific geographical context). The system model of the soy biodiesel supply chain is expanded to encompass the production of the substituted marginal market equivalent (rapeseed meal), whose inventory is subtracted from that of the biodiesel supply chain inventory in order to estimate the impacts of biodiesel production. The results are hence intended to represent the net environmental impacts of the increase in soy biodiesel production in the economic system as a whole.

The understanding of LCA that underpins the consequential approach emphasizes its holistic and comprehensive nature at the market (economy) level. In this light, in addition to the direct linkages typically considered in attributional life cycle-based supply chain modeling, achieving comprehensiveness demands that one cannot ignore the indirect (market-mediated) effects that may occur due to changes in product systems as result of inter-linkages with other product systems. In order for consequential LCA models to be consistent with this understanding of the nature and purpose of LCA when solving multi-functionality problems, indirect, marketmediated effects must be accommodated. For this reason, system expansion + substitution may be the only possible approach to resolving multi-functionality problems in consequential LCA - meaning that a multi-functionality hierarchy is, per se, unnecessary when employing this data modeling approach.

\subsubsection{System expansion + substitution in attributional data modeling}

In assessments using an attributional data modeling approach, the purpose is to estimate the absolute impacts of a product system at/up to a given point in time (past, present, or future). The model is intended to present a snap shot or static view of the product system. The use of system expansion in the sense in which it is used in consequential data modeling does not "fit" with attributional data modeling. Nevertheless, approaches inspired by system expansion, including substitution, are sometimes employed by practitioners. It is important to carefully consider the practical implications of these approaches.

In an attributional context, substitution can essentially be used as a basis for allocation. Take as an example a milk production system that produces both milk and calves (for meat). The burdens associated with milk production only 
might be calculated by subtracting the inventory for producing beef calves in a meat-only beef production system from the inventory of the combined meat and dairy system. In effect, beef calves serve as a proxy for dairy calves in this example. In other words, despite likely differences in the input/output flows characteristic of beef versus dairy calf production, they are assumed to be equivalent (Heijungs and Guinée 2007).

\subsubsection{Analysis of system expansion and substitution}

The current status of subdivision and system expansion, if understood as reporting at the level of all co-products, in the first tier of the ISO 14044 multi-functionality hierarchy is defensible from a physical modeling perspective (see below), since these options are most likely to maintain the integrity of the physical relationships modeled. The notion that system expansion and substitution are commensurate, along with the preferred status it confers to substitution in attributional data modeling contexts is, however, contentious among some practitioners (Guinée et al. 2002; Heijungs and Guinée 2007; Mathiesen et al. 2009; Wardenaar et al. 2012; Zamagni et al. 2012)

In consequential data modeling, the degree of representativeness and robustness of LCA models using system expansion + substitution to solve multi-functionality problems will depend on how accurately the assumed substitution scenarios are defined. In practice, the assumptions regarding the one-toone substitutions of marginal market equivalents that can be central to consequential modeling are questionable and may cast doubt as to the realism of the resultant model outcomes (Ekvall and Finnveden 2001; Guinée et al. 2002; Heijungs and Guinée 2007; Pelletier 2010; Pelletier and Tyedmers 2011; Brander and Wylie 2011; Zamagni et al. 2012). In reality, markets will seldom (if ever) be as predictable as such models/assumptions imply. Moreover, according to some LCA practitioners (for example, see Niederl-Schmidinger and Narodoslawsky 2008; Mendoza et al. 2008; Beccali et al. 2010), it is often difficult (and sometimes impossible) to even identify a substitution scenario due to the uniqueness of the production process. As highlighted by Heijungs and Guinée (2007), substitution imposes a philosophical problem: "how can one decide which process is avoided given the fact that it is avoided, and hence not there?" Although system expansion + substitution is, per se, the only possible approach to resolving multi-functionality problems in consequential modeling, it might therefore be argued that consequential models should be explicitly presented as scenarios, with all such assumptions and limitations clearly described (Heijungs and Guinée 2007; Zamagni et al. 2012).

The use of system expansion + substitution as a basis for allocation in attributional data modeling similarly faces several challenges. Substitution-based allocation in attributional modeling can be conducted either by considering identical products or products which are functionally equivalent (i.e., having the same functional unit). Where there are multiple possible substitution options for the same products that are produced using different methods or that provide the same functional unit, then multiple scenarios and assessment results are possible. This can lead to substantially different results, depending on the substitution scenario considered (Heijungs and Guinée 2007). When substitution requires the use of proxies (as in the previous dairy/calves example), the model results may be poorly representative of the actual system and its associated burdens.

Similar challenges arise in the case of the so-called credits given for net energy in attributional LCAs. In a consequential assessment, the energy is assumed to displace provision of energy that would otherwise be produced by other technologies. In attributional assessments, which consider static situations rather than change, this distinction is problematic. Rather, net energy should be reported in the inventory as a result. We may then consider how this energy is actually used and what would be the actual alternative fuel (or what was the actual alternative before). The inventory for the alternative fuel is then subtracted from the product system inventory as a "credit."

In sum, in contrast to consequential data modeling, where the rationale for preferring (indeed, requiring) system expansion and substitution is clear, this does not seem to be the case for use of system expansion and substitution in attributional data modeling. It is therefore questionable as to whether system expansion, when understood to include substitution, should be considered a priority option in attributional data modeling, as may be interpreted in the current ISO 14044 hierarchy.

3.2 Allocation based on an underlying physical relationship: approaches and supporting rationales

Proponents of physical allocation primarily view attributional LCA as a physical, natural science-based modeling framework, where the (physical) flows of material and energy characteristic of a product system (life cycle inventory) are compiled and modeled in such a way as to support quantification of associated burdens (life cycle impact assessment) on the basis of direct, physical relationships between inputs, outputs (co-products and emissions), and impacts. Where subdivision or system expansion (understood simply as modeling and reporting at the system-level rather than modeling substitution scenarios) is not possible, proponents of this approach hence ascribe to the second tier of the IS0 14044 multi-functionality hierarchy, which stipulates that "where allocation cannot be avoided, the inputs and output of the system should be partitioned between its different products or 
functions in a way that reflects the underlying physical relationships between them." The prioritization of this approach is seemingly supported by the further guidance to the hierarchy specified in ISO 14044, which states that "the inventory is based on material balances between inputs and outputs. Allocation procedures should therefore approximate as much as possible such fundamental input/output relationships and characteristics." It is similarly in line with the natural science approach that is prioritized in ISO 14040 (clause 4.1.8) (ISO 2006b). Other standards that provide more prescriptive guidance than ISO 14044 and also prioritize physical allocation include the European Commission PEF/OEF guides (EC 2013a, b) and the ETSI TS 103199 (for LCAs of ICT equipment, networks, and services) (ETSI 2011). The latter requires allocation between services and equipment, etc. based on criteria such as use time and traffic.

Contrary to ISO 14040, however, this perspective rejects that where natural science approaches are not possible, then approaches from social and economic sciences or decisions based on other value choices should be used (i.e., the third tier of the ISO 14044 hierarchy) on the basis that the latter may produce model results of questionable physical representativeness. Rather, it is held that attributional LCA model outputs will only be representative, meaningful, and useful for environmental management if they actually reflect the physical reality associated with the modeled processes (Pelletier and Tyedmers 2011, 2012).

Due to this emphasis on maintaining physical realism in LCA models, some proponents of this approach have been strongly critical of the use of market information in LCA, wherever use of such information results in distortions of the physical relationships that LCA models are thought to be intended to represent (Pelletier and Tyedmers 2010, 2012 and references therein). Examples of instances where the use of market information is thought to distort the physical realism of LCA models include the following: consequential data modeling based on assumed but inaccurate, market-mediated product substitutions; attributional data modeling using economic allocation; and where the distinction between coproduct and waste applied in LCA is based on economic value (see respective sections).

For the analytical results from LCA studies to be relevant for environmental management, however, some authors have underscored that it is also crucial that such solutions not be arbitrary (as is often the case when solutions such as massbased allocation are generically applied to multi-functionality problems without regard to the specific context) (Pelletier and Tyedmers 2011, 2012). Toward this end, it is suggested that the current wording "underlying physical relationship" in the ISO hierarchy be revised to specify "relevant underlying physical relationship." An example of relevance in this context might be a physical property relevant to the defined primary function of the co-product of interest that is also a reasonable common denominator for allocation between the co-products. In this way, the model will result in a direct quantification of the environmental implications of providing the defined function (or a component thereof) based on physical relationships between the inputs and outputs (Pelletier and Tyedmers 2011, 2012). Attributed burdens can subsequently be compared among alternative means of providing the same functional attribute via competing processes. Where several functional attributes are relevant (for example, protein, energy, or essential fatty acids for seafood processing co-products), each can subsequently be applied in turn as allocation criteria in order to understand the environmental implications of operating the product system for specified ends (i.e., the various functional attributes it provides). This would appear to be consistent with the ISO 14044 recommendation for a sensitivity analysis where several allocation criteria are potentially relevant. Exergy or other thermodynamic measures may provide a basic "common denominator" for physical allocation where necessary and/or appropriate.

The physical approach has been advocated by several authors in a variety of contexts - in particular, with respect to food production systems (Lundie et al. 2007; Schau and Fet 2008; Pelletier and Tyedmers 2010; Ziegler et al. 2012; Pelletier et al. 2014). For example, Lundie et al. (2007) develop a physicochemical allocation matrix for the dairy industry and highlight the importance of industry specific allocation procedures that reflect causal physical relationships. In a similar vein, Schau and Fet (2008) propose that "biological causality," in direct parallel to the more generic term "physical causality" used in ISO 14044, may be most appropriate in many food LCA contexts.

An example of using a physical relationship as a basis for allocation is apportioning burdens in a soy biodiesel feedstock supply chain between the oil (used for biodiesel) and meal (used for animal feed) fractions produced by processing soy beans based on their respective energy content. The relationship could be deemed appropriate from a physical perspective because (1) the relevant function of the co-product of interest (soy oil) is as an energy carrier, but energy also represents a potential common denominator for the functions of both coproducts (i.e., feed energy and fuel energy); (2) for the crop system, the amounts of material/energy inputs allocated by the plants to producing the protein (soy meal) and fat (soy oil) molecules is reflected in their respective energy densities; and (3) allocation based on energy content produces results that reflect the efficiency of the product system in providing the defined function.

\subsubsection{Criticisms of allocation based on an underlying physical relationship}

Based on an analysis of the ISO 14044 hierarchy, Guinée et al. (2002) discuss the distinction between the two categories of 
what ISO refers to as allocation. The first category refers to instances of multi-functionality problems that can be resolved by partitioning unit processes and resultant emissions in an empirical manner based on an underlying physical relationship. The second category refers to instances where an underlying physical relationship cannot be identified, and hence, some other solution is necessary. In the case of the latter, Frischnecht $(1998,2000)$ and Guinée et al. (2002) suggest that the multi-functionality problem is an artifact of attempting to isolate one function out of many and that since artifacts can only be cured in an artificial way, there is no correct way of solving the multi-functionality problem. With respect to ISO 14044, allocation based on an underlying physical relationship corresponds to the former aspect, whereas as allocation based on "some other relationship" (i.e., third tier of ISO 14044) corresponds to the latter. However, the authors further interpret that the second tier of the hierarchy includes both "causal" physical relationships, as well as "other physical relationships," which they describe as providing for "somewhat artificial solutions." This view has been contested elsewhere (Huppes and Schneider 1994; Ekvall and Finnveden 2001).

It therefore bears further consideration and clarification as to what actually does qualify as "allocation based on an underlying physical relationship"- something that is unclear in the current ISO 14044 standard. In some instances, allocation based on an underlying physical relationship might be better understood as subdivision. For example, assuming that vacuum cleaners are used under the same working conditions and in the same way for cleaning both hotel rooms and conference rooms in joint hotel/conference facilities, thus consuming the same amount of electricity per surface area cleaned, allocating impacts of cleaning between hotel and conference services in proportion to surface area might be considered a form of subdivision rather than allocation based on an underlying physical relationship.

Other authors have suggested that allocation solutions employing physical criteria that cannot be considered reflective of a causal relationship should be classed in the third tier of the ISO hierarchy (for example, see Huppes and Schneider 1994; Ekvall and Finnveden 2001). This includes what critics refer to as arbitrary applications of criteria such as mass, volume, or energy content when these do not reflect "the way in which the inputs and output are changed by quantitative changes in the products or functions delivered by the system" (Guinée et al. 2002). For example, referring to the allocation of impacts from petroleum refineries to bitumen and other co-products, ISO/TR 14049 (ISO 2012) states that any physical parameter (e.g., mass, feedstock energy, thermal conductivity, viscosity, and specific mass) could be taken into consideration, "but none of those parameters can be justified to be preferable to the other ones. The fact that in this example the ratio between the bitumen and the other co-products cannot be varied indicates that physical allocation cannot be applied." Any arbitrary selection of a physical criterion increases the likelihood of inconsistency between otherwise similar studies and may also produce results of questionable relevance.

In addition, qualitative properties may at times be determining for the functional attributes of co-products (for example, taste, beauty, fashion, and comfort) (Ardente and Cellura 2012). Such qualities may not be reducible to physical criteria. Here, allocation based on an underlying physical relationship would produce results that do not reflect the efficiency of the system in providing the functional attributes. Moreover, it may not be possible to identify a single physical criterion, regardless of whether or not it can be considered relational, that adequately represents the multiple, complex functional attributes of the product in question (see section on economic allocation). In such cases, it might be argued that whenever co-products differ in terms of specific qualities that cannot be measured by physical criteria, allocation based on other relationships should be preferred (including, for example, allocation based on the market prices of co-products).

Allocation (both physical and economic) has also been criticized by Weidema and Schmidt (2010) on the basis that balances between inputs and output are only maintained for the criterion used as the allocation key. For example, if energy is used as the allocation criterion, then mass imbalances will result (and vice versa). These critics also charge that any form of allocation, including physical allocation, unnecessarily truncates system boundaries, hence resulting in an artificially delimited analysis and results.

\subsection{Economic allocation: approaches and supporting rationales}

Following the ISO 14044 (2006a, multi-functionality hierarchy, "where a physical relationship alone cannot be established or used as the basis for allocation, the inputs should be allocated between the products and functions in a way that reflects other relationships between them." In practice, allocation in proportion to the economic value of coproducts has been the prevalent (if not exclusive) application of this provision. Moreover, despite its current placement (as an example) in the lowest tier of the ISO 14044 allocation hierarchy, economic allocation is one of the most widely applied multi-functionality solutions in published LCA studies across sectors (Werner and Richter 2000; Thrane 2006; Ayer et al. 2007; Beccali et al. 2010; Van der Voet et al. 2010; EC 2010).

A variety of closely related rationales have been advanced in support of economic allocation. The most common of these is that the generation of economic value is what motivates production processes; hence, the share of value attributable to the production of co-products constitutes an appropriate basis 
for apportioning "responsibility" for the associated environmental burdens (Peereboom et al. 1999; Guinée et al. 2004; Mendoza et al. 2008; Weinzettel 2012). With respect to identifying the functional unit, ISO/TR 14049 (2012) states that "the functions are typically related to specific product or process properties, each of which may fulfill specific needs and thereby have a use value, which typically creates economic value to the supplier of the product." Huppes (1993) is also explicit in this line of argument, stating that "in a social sense, the value created causes the process. If no value is created, the process will soon cease to exist and no environmental interferences will result." Analogously, Peereboom et al. (1999) argue that "from a chemical engineering point of view, it is more logical to use mass allocation rather than economic allocation. On the other hand, economic allocation better represents the societal cause of the emissions."

This "social causality" argument is intended to parallel the "physical causality" rationale that may be interpreted to underpin multi-functionality solutions in the first two tiers of the ISO 14044 hierarchy. Central to this argument is the corollary assumption that allocation should reflect the principle of "fairness" (Kloepffer 1996; Frischnecht 1998, 2000).

A closely related argument advanced by Ardente and Cellura (2012) is that economic allocation is merited where co-products/co-services have intrinsic qualities that physical parameters cannot adequately reflect. Here, it is recognized that prices represent aggregate proxies for the complex quality attributes inherent to many products and services (e.g., artistic, cultural, or other subjective properties such as taste or beauty), which cannot be communicated in terms of single physical attributes. Hence, differences in the prices of co-products reflect the balance of the qualities of the products that are decisive to user choice. This argument also corresponds to the previously described rationale for allocation based on social causality and for distributing responsibility for burdens in proportion to benefits conferred (fairness).

Another related argument is that economic allocation may be a preferable option where other (physical) criteria result in the attribution of a large proportion of burdens to low-value co-products (as for example, the joint mutually dependent mining of gold and copper, as described by Weinzettel 2012). The implicit rationale here is that LCAs should not produce results that are counter-intuitive (i.e., because they are contrary to price ratios or to preconceptions regarding the relative importance of co-products, generally). Again, this argument may be related to intuitions regarding social causality and fairness/responsibility.

A final rationale for economic allocation that has been described is that it facilitates producing LCA model outcomes that may incentivize desired behaviors - in particular, increased use of low-value co-products (for example, see Weinzettel 2012) in order to increase industrial ecological efficiencies. Similar arguments have been made in support of basing the distinction between products and wastes in LCA on economic value. Here, products are defined as those output flows with positive market value, whereas wastes are those with zero or negative market value. This criterion has been adopted or advocated in several contexts to date (Huppes 1993; OECD 1998; Guinée et al. 2004; EC 2010; WRI/WBCSD 2011; Ardente and Cellura 2012; Weinzettel 2012).

These related rationales in support of economic allocation point toward specific conceptions of the nature and purpose of LCA, along with the modeling decisions necessary to satisfy them. Following the distinction made by Tillman (2000) between cause-oriented and effect-oriented causality, those arguments emphasizing social causality/fairness might be classified as "cause-oriented" whereas those emphasizing incentives as "effect-oriented." In the case of arguments based on social causality (and the corresponding link to the principle of fairness), the modeling choice (economic allocation) is made for the purpose of ensuring that the model outcomes fairly apportion burdens in relation to benefits (expressed by revenues) gained. In the case of arguments for incentivizing desired behaviors, the modeling choice is made for the purpose of achieving a pre-ordained desirable social outcome (for example, reduced waste). At root of both is the notion that LCA is not a purely physical modeling framework but rather one that can/should accommodate normative social orientations. In this light, a core purpose of LCA is to provide support to furthering such normative orientations. From this perspective, the current lowest-tier status of economic allocation in the ISO multi-functionality hierarchy is inappropriate. This could only be resolved by modifying the current hierarchy such that economic allocation is prioritized wherever allocation is necessary.

A representative example of economic allocation is apportioning burdens at a fur farm between the co-products, fur $(0.5 \mathrm{~kg})$ and meat $(2 \mathrm{~kg})$, based on their relative market values (3,333 euros/kg versus 5 euros/ $\mathrm{kg}$, respectively). In this case, $99.4 \%$ of burdens are allocated to the fur and $0.6 \%$ to the meat. The core argument in support of such a solution is that the relevant properties of the co-products that are determining for consumer preferences (and hence producer motivations to run the fur farm) are very different (for example, taste/texture in the case of meat versus softness/prestige in the case of fur). They hence cannot be accommodated by system expansion (if co-product level reporting is desired and/or appropriate substitutes cannot be identified) or physical allocation strategies (which may have the counter-intuitive effect of attributing the majority of burdens to the lower value meat co-product). In the case of the latter, one could imagine a scenario where a reduction in demand (and revenues) for the meat co-product due to high attributed burdens would result in its disposal rather than productive use: in this case, all impacts would be attributed to the fur. In contrast, economic allocation in this 
context apportions responsibility for burdens to co-products using a proxy (revenues) that proponents of this approach believe more accurately and fairly reflects these complex, socially causal attributes.

\subsubsection{Criticisms of economic allocation}

From a physical perspective, economic allocation in attributional LCA inevitably produces results that reflect existing market relationships (via price ratios) rather than the physical relationships that characterize the system in question and which (it is held) an LCA model is intended to make visible. A direct consequence of using economic allocation is that the resultant model outcomes tend to suggest that economically cheap is commensurate with environmentally benign (Pelletier and Tyedmers 2011, 2012). In the previous scenario of economic allocation between meat and fur co-products, for example, since the fur is apportioned $99.6 \%$ of the impacts, the meat co-product may appear to be environmentally preferable to meat from animals with less valuable fur regardless of the actual comparative environmental costs of producing the different animals. In essence, the "signal" provided by models using this criterion is that buying the cheapest coproducts (whether for final consumption or as inputs to other production processes) may be an effective means of reducing one's own environmental impacts.

This is thought by some to be contrary to the purpose and potential utility of LCA - in particular, in regard to informing remedies to environmental externalities (Pelletier and Tyedmers 2011, 2012). A model that ascribes a small fraction of burdens to a co-product simply because it is inexpensive compared to the other co-products is effectively blind to the relative ecological efficiency of the system in question compared to alternative systems that provide the same product. In contrast, from a physical perspective, a more appropriate basis for apportioning burdens in the previous meat/fur example might be in proportion to the biological energy flows respectively devoted by the animal to producing the meat and fur coproducts, since this more accurately reflects the actual physical flows and associated burdens attributable to production of each.

Similar criticisms apply to the practice of distinguishing between products and wastes based on the values of output, which may produce results that vary widely with changing market conditions, regardless that the physical flows that are characteristic of the system, and the resulting environmental burdens, do not change. From the physical perspective, the more appropriate distinction is thought to be whether or not a co-product is, in fact, further productively utilized in another process (Pelletier and Tyedmers 2011, 2012). This understanding is consistent with the current ISO 14044 (2006a, b) standard, which defines waste simply as "substances or objects which the holder intends or is required to dispose of."
Beyond the issue of physical representativeness, some criticisms also arise with respect to invoking the concept of "fairness" or the desirability of incentivizing particular behaviors (e.g., the utilization of co-products that might otherwise be destined for disposal, in the interest of efficiency) in support of economic allocation. What results is the creation of a model for the express purpose of generating a predetermined normative outcome (i.e., according to a particular belief system). These are certainly important principles, but they are not consistent with the physical approach to LCA that is advocated by some practitioners (Pelletier and Tyedmers 2011, 2012) nor with the "natural science" approach that is seemingly prioritized in ISO 14040. On the other hand, some authors underscore that (as in other natural sciences) LCA is anyway inescapably affected by value judgments and preferences that conflict with the general goal of objectivity (Hertwich et al 2000).

It is also recognized that economic allocation is subject to several uncertainties, in particular related to price variability, which reflects dynamics other than the considered process (Guinée et al. 2004). Problems may also arise when markets (and therefore prices) are missing (e.g., in the case of intermediate products exchanged between unit processes). In this case, additional assumptions must be introduced in the analysis. Furthermore, prices of products and revenues can be affected by distortion effects, as with imperfectly competitive markets (e.g., monopolies or oligopolies) or when there are government interventions (e.g., subsidies or compulsory requirements) (Guinée et al. 2004). Guinée et al. (2004) suggest solutions for such problems.

\subsection{Competing preferred multi-functionality hierarchies}

For each of these three schools of thought regarding preferred multi-functionality problem solutions, avoiding allocation via subdivision is a preferred solution. Beyond this initial point of agreement, however, we suggest that none actually map directly with the existing ISO 14044 hierarchy. Instead, three alternative hierarchies are implied, one of which corresponds to consequential data modeling applications and the other two to attributional data modeling applications (Table 1).

It is difficult to conclude with any certainty to what extent researchers choose to ignore the ISO 14044 hierarchy based on specific personal interpretations of the nature of LCA and the preferred multi-functionality solutions that support them. In some cases, it may equally be the case that researchers interpret the "wherever possible" and "should" terms employed in the descriptions of each tier of the ISO hierarchy as having precedence over the preceeding "shall" prescription to observe the hierarchy in solving multi-functionality problems. Also unclear is the extent to which the ISO 14044 requirement that modeling choices reflect the goals and scope 
Table 1 Alternative multi-functionality hierarchies consistent with competing understandings of the nature, purpose, and conditions necessary to LCA

\begin{tabular}{|c|c|c|c|c|}
\hline & \multirow[b]{2}{*}{ ISO 14044} & \multirow{2}{*}{$\begin{array}{l}\text { Consequential data modeling } \\
\text { approach } \\
\text { Change-oriented, } \\
\text { systems perspective }\end{array}$} & \multicolumn{2}{|l|}{ Attributional data modeling approach } \\
\hline & & & $\begin{array}{l}\text { Physical perspective } \\
\text { (natural science-based/physical realism) }\end{array}$ & $\begin{array}{l}\text { Socioeconomic perspective } \\
\text { (fairness/incentives) }\end{array}$ \\
\hline Tier 1 & $\begin{array}{l}\text { Avoid allocation via } \\
\text { subdivision or system } \\
\text { expansion }\end{array}$ & $\begin{array}{l}\text { Avoid allocation via subdivision } \\
\text { or "system expansion }+ \\
\text { substitution" }\end{array}$ & $\begin{array}{l}\text { Avoid allocation via subdivision or } \\
\text { system expansion (reporting at } \\
\text { level of all co-products) }\end{array}$ & $\begin{array}{l}\text { Avoid allocation via subdivision or } \\
\text { system expansion (reporting at } \\
\text { level of all co-products) }\end{array}$ \\
\hline Tier 2 & $\begin{array}{l}\text { Allocation based on an } \\
\text { underlying physical } \\
\text { relationship }\end{array}$ & NA & $\begin{array}{l}\text { Allocation based on a relevant } \\
\text { underlying physical relationship }\end{array}$ & $\begin{array}{l}\text { Allocation based on the relative } \\
\text { economic value of co-products }\end{array}$ \\
\hline Tier 3 & $\begin{array}{l}\text { Allocation based on some } \\
\text { other relationship }\end{array}$ & NA & NA & NA \\
\hline
\end{tabular}

NA not applicable

of the analysis is consistent with prescription of a hierarchy, regardless of its substantive content.

We posit that, at least in some instances, choice among these hierarchies described above will, indeed, primarily reflect a practitioners pre-existing orientations and understanding of the nature/purpose of LCA as opposed to simple observance of the ISO 14044 hierarchy. For consequential LCA, system expansion + substitution is the only modeling choice that supports the corresponding defined nature and purpose of LCA (i.e., change-oriented, system-level modeling, taking into account indirect, market-mediated effects). Allocation should, in theory, never be necessary. From the physical perspective, maintaining the natural science basis of the model constitutes the core criterion for selection of a multifunctionality solution. In this light, assumed market-mediated substitutions are questionable in terms of the extent to which they reasonably represent physical reality, and economic allocation does not, in any circumstance, constitute a defensible modeling choice. From the socioeconomic perspective, in contrast, fairly reflecting social causality and/or incentivizing particular behaviors are emphasized; hence, allocation in proportion to the economic value of co-products is preferred. In corollary, arbitrary applications of physical criteria which do not reflect such social causality are thought to produce arbitrary results and are hence viewed as undesirable. Each of these positions is internally consistent but seemingly mutually exclusive. We hence question the extent to which they can actually be reasonably accommodated in the context of a single hierarchy, as in ISO 14044, unless one approach is clearly prioritized, along with a supporting rationale, over the other.

Some LCA practitioners may claim to confer equal validity to the different supporting understandings of the nature and purpose of LCA we describe here, and instead advocate adherence to a more general "causality" principle for the partitioning of impacts on a case-by-case basis. In other words, the allocation strategy would be chosen with respect to context, with the practitioner selecting from among several possible alternative causality principles (including physical, economic, or possibly others) related to the selected functional unit(s) and/or the goals of the LCA. However, as we demonstrate, arguments for particular forms of causality are based on very different underpinning assumptions regarding the nature and purpose of LCA. It is hence difficult to see how advocating causality in general as a basis for allocation would contribute to improved clarity and consistency in practice.

\section{Conclusions}

We identified and compared the rationales for (and limitations of) different common approaches to solving multifunctionality problems in LCA. We note that, although the current ISO hierarchy suggests a prioritization of natural science-based approaches to multi-functionality solutions, this prioritization (1) is not made clearly, (2) is not supported by a clearly defined rationale, and (3) may not be shared by all LCA practitioners. We suggest that this lack of universal acceptance may explain some of the observable inconsistency in multi-functionality problem-solving in LCA studies.

System expansion + substitution is clearly the preferred approach in consequential data modeling contexts, since the specific purpose of this modeling approach is to model the effects of changes in demand for a product, including changes in different - but interacting - product systems. For consequential LCA, a multi-functionality hierarchy may hence be unnecessary. We foresee, however, that challenges may arise when product substitutes cannot be clearly identified.

In attributional data modeling contexts, we suggest that system expansion can be understood to refer to expanding the functional unit to include all of the co-products (hence avoiding the need for allocation by modeling and reporting results at the system rather than co-product level), without subsequently modeling product substitutions. We underscore that system expansion + substitution (as in consequential data modeling) may be difficult to meaningfully accommodate in 
attributional data modeling contexts. Identifying single product systems that provide functionally equivalent products may not be possible. Moreover, the use of inventories from other product systems as proxies for inventories of co-products will not provide realistic results unless their inventory profiles are identical. We hence suggest that this approach should not be prioritized in attributional data modeling.

With respect to allocation, we identify two distinct schools of thought. Advocates of physical allocation emphasize that multi-functionality solutions should be chosen so as to maintain the natural science basis of an LCA model in order to obtain physically representative model outcomes. In contrast, those who advocate the use of economic allocation emphasize the importance of fairly reflecting socioeconomic causality and/or incentivizing particular behaviors. We conclude that these two approaches to allocation in attributional data modeling are based on internally consistent but mutually exclusive rationales. In other words, the arguments used in support of each approach stem from different underpinning assumptions as to the nature and purpose of LCA. It is hence difficult to accommodate these two approaches in a single multifunctionality hierarchy without explicitly prioritizing one approach and its supporting rationale over the other.

We suggest that the choice of a multi-functionality solution should never be arbitrary but rather always be based on a clearly justified rationale that directly corresponds to the goal and scope of the study. Transparency with respect to these decisions is essential.

We underscore the importance of a common multifunctionality hierarchy for increasing consistency in LCA practice and hence improving the credibility and acceptability of LCA as a decision-support tool. Toward this end, some possible solutions that might be entertained in a future, revised version of ISO 14044 are as follows:

- Clearly differentiate between consequential and attributional data modeling approaches, with guidance for each as to appropriate multi-functionality solutions (in particular, with respect to the meaning and application of system expansion and/or substitution).

- Require that practitioners clearly and transparently describe the rationale for their chosen approach to solving multi-functionality problems and, if applicable, a justification for not following the ISO multi-functionality hierarchy, including explanations of why higher tier solutions were not employed. Here, examples of acceptable justifications would be useful.

- Provide a clear rationale for the prioritization of natural science-based multi-functionality solutions. A clearly described rationale might appeal to some practitioners who currently favor a socioeconomic basis for solving multifunctionality problems, and hence increase consistency in practice.
- Differentiate between natural science and socioeconomic based approaches to attributional data modeling. Practitioners of attributional LCA could then be required to identify and justify which approach they choose as part of the goal and scope definition and that their multifunctionality solutions be chosen and justified accordingly.

- Provide stronger requirements regarding the use of sensitivity analyses for multi-functionality solutions. For consequential data modeling, this refers to testing the influence of assumed substitution scenarios. For attributional data modeling, we suggest that sensitivity analysis can be applied within natural science-based approaches (i.e., testing the influence of using different, relevant physical allocation criteria) and socioeconomic-based approaches (testing the influence of using different relevant socioeconomic criteria). It can also be used to demonstrate the influence of using a natural science versus a socioeconomic approach to solving multi-functionality problems by comparing the use of physical versus economic allocation.

\section{References}

ADEME (2010) BP X30-323 - Repository of Good practices. French agency for the environment and energy management, Paris

Andrae A, Andersen O (2010) Life cycle assessments of consumer electronics - are they consistent? Int J Life Cycle Assess 15(8):827-836

Ardente F, Cellura M (2012) Economic allocation in life cycle assessment. The state of the art and discussion of examples. J Ind Ecol 16(3):387-398

Ayer N, Tyedmers P, Pelletier N, Sonesson U, Scholz A (2007) Coproduct allocation in life cycle assessments of seafood production systems: review of problems and strategies. Int J Life Cycle Assess 12(7):480-7

Beccali M, Cellura M, Iudicello M, Mistretta M (2010) Life cycle assessment of Italian citrus-based products: sensitivity analysis and improvement scenarios. J Environ Manag 91(7):1415-1428

Brandão M (2012) Food, feed, fuel, timber or carbon sink? Towards sustainable land-use systems - a consequential life-cycle approach. Centre for Environmental Strategy, Faculty of Engineering and Physical Sciences. Guildford, UK, University of Surrey. PhD

Brander M, Wylie C (2011) The use of substitution in attributional life cycle assessment. GHG Meas Manag 1(3-4):161-6

EC (2010) The International Reference Life Cycle Data System (ILCD) Handbook - General guide for Life Cycle Assessment - Detailed guidance. European Commission, Joint Research Centre. Publications office of the European Union, Luxemburg

EC (2013a) Organisation Environmental Footprint (OEF) Guide. Directorate General - Joint Research Centre, European Commission

EC (2013b) Product Environmental Footprint (PEF) Guide. Directorate General - Joint Research Centre - European Commission

Edwards R, Mulligan D, Marelli L (2010) Indirect land use change from increased biofuels demand: Comparison of models and results for marginal biofuels production from different feedstocks. European Commission, Joint Research Centre. Publications office of the European Union, Luxemburg 
Ekvall T, Andrae A (2006) Attributional and consequential environmental assessment of the shift to lead-free solders. Int J Life Cycle Assess 11(5):344-353

Ekvall T, Finnveden G (2001) Allocation in ISO 14041 - a critical review. J Clean Prod 9(3):197-208

Ekvall T, Tillman A-M (1997) Open-loop recycling: criteria for allocation procedures. Int J Life Cycle Assess 2:155-162

Ekvall T, Weidema B (2004) System boundaries and input data in consequential life cycle inventory analysis. Int J Life Cycle Assess 9(3):161-171

ETSI (2011) ETSI TS 103 199 V1.1.1 Environmental Engineering (EE); Life Cycle Assessment (LCA) of ICT equipment, networks and services; general methodology and common requirements. European Telecommunications Standards Institute. http://www. etsi.org/deliver/etsi ts/103100 103199/103199/01.01.01 60/ts 103199v010101p.pdf

Finnveden G, Lindfors L-G (1998) Data quality of life cycle inventory data-rules of thumb. Int J Life Cycle Assess 3:65-66

Frischknecht R (1998) Life cycle inventory analysis for decision-making: Scope-dependent inventory system models and context-specific joint product allocation. 3-9520661-3-3. Eidgenössische Technische Hochschule Zürich, Switzerland

Frischknecht R (2000) Allocation in life cycle inventory analysis for joint production. Int J Life Cycle Assess 5(2):85-95

Guinée J (ed) (2002) Handbook on life cycle assessment. Operational guide to the ISO standards. I: LCA in perspective. IIa: Guide. IIb: Operational annex. III: Scientific background. Kluwer Academic Publishers, Netherlands

Guinée J et al (2002) Handbook on life cycle assessment: operational guide to the ISO standards. Int J Life Cycle Assess 7(5):311-3

Guinée J, Heijungs R, Huppes G (2004) Economic allocation: examples and derived decision tree. Int J Life Cycle Assess 9(1):23-33

Heijungs R, Guinée JB (2007) Allocation and 'what-if' scenarios in life cycle assessment of waste management systems. Waste Manag 27(8):997-1005

Hertwich EG, Hammitt JK, Pease WS (2000) A theoretical foundation for life-cycle assessment. Recognizing the role of values in environmental decision making. J Ind Ecol 4(1):13-28

Huppes G (1993) Macro-environmental policy: principles and design: with cases on milk packaging, cadmium, phosphorus and nitrogen, and energy and global warming. CML Publisher, Leiden

Huppes G, Schneider F (1994) Proceedings of the European workshop on allocation in life cycle assessment. Leiden University, Netherlands

ISO (2006a) ISO 14044: Environmental management-life cycle assessment-requirements and guidelines. The International Organization for Standardization (ISO), Geneva, Switzerland

ISO (2006b) ISO 14040: Environmental management — life cycle assessment-principles and framework. The International Organization for Standardization (ISO), Geneva, Switzerland

ISO (2012) ISO/TR 14049: Environmental management-life cycle assessment-illustrative examples on how to apply IS0 14044 to goal and scope definition and inventory analysis. The International Organization for Standardization (ISO), Geneva, Switzerland

Kloepffer W (1996) Allocation rule for open-loop recycling in life cycle assessment. Int J Life Cycle Assess 1(1):27-31

Kløverpris J et al (2008) Life cycle inventory modelling of land use induced by crop consumption. Part 1: conceptual analysis and methodological proposal. Int J Life Cycle Assess 13(1):13-21

Lund $\mathrm{H}$ et al (2010) Energy system analysis of marginal electricity supply in consequential LCA. Int J Life Cycle Assess 15:260-271

Lundie S, Dennien G, Morain M, Jones M (2007) Generation of an industry-specific physico-chemical allocation matrix. Application in the dairy industry and implications for systems analysis. Int $\mathrm{J}$ Life Cycle Assess 12(2):107-117
Mathiesen B, Munster M, Fruergaard T (2009) Uncertainties related to identification of the marginal energy technology in consequential life cycle assessments. J Clean Prod 17(15): $1331-1338$

Mendoza A, van Ruijven T, Vad K, Wardenaar T (2008) The allocation problem in bio-electricity chains. Report of a Project Group as part of the MSc. Leiden, The Netherlands: Industrial Ecology, Institute of Environmental Sciences (CML)

Niederl-Schmidinger A, Narodoslawsky M (2008) Life cycle assessment as an engineer's tool? J Clean Prod 16(2):245-252

OECD (1998) Final guidance document for distinguishing waste from non-waste. Organisation for Economic Co-operation and Development, Paris

Peereboom E, Kleijn R, Lemkowitz S, Lundie S (1999) Influence of inventory data sets on life-cycle assessment results: a case study on PVC. J Ind Ecol 2(3):109-130

Pelletier N (2010) What's at steak? Ecological economic sustainability, and the ethical, environmental, and policy implications for global livestock production. PhD thesis, Dalhousie University, Canada

Pelletier N, Tyedmers P (2010) Life cycle assessment of frozen tilapia fillets from Indonesian lake-based and pond-based intensive aquaculture systems. J Ind Ecol 14(3):467-481

Pelletier N, Tyedmers P (2011) An ecological economic critique of the use of market information in life cycle assessment research. J Ind Ecol 15(3):342-54

Pelletier N, Tyedmers P (2012) Response to Weinzettel. J Ind Ecol 16(3): 456-458

Pelletier N, Allacker K, Pant R, Manfredi S (2014) The European Commission Organisation Environmental Footprint Method: comparison with other methods, and rationales for key requirements. Int J Life Cycle Assess 19:387-404

Reap J, Roman F, Duncan S, Bras B (2008) A survey of unresolved problems in life cycle assessment. Part 1: goal \& scope and inventory analysis. Int $\mathrm{J}$ Life Cycle Assess 13(4):290-300

Schau E, Fet A (2008) LCA studies of food products as background for environmental product declarations. Int J Life Cycle Assess 13(3): 255-264

Thrane M (2006) LCA of Danish fish products. Int J Life Cycle Assess 11(1):66-74

Tillman AM (2000) Significance of decision-making for LCA methodology. Environ Imp Assess 20:113-123

Tillman AM et al (1994) Choice of system boundaries in life cycle assessment. J Clean Prod 2(1):21

UNEP/SETAC (2011) Global guidance principles for life cycle assessment databases - a basis for greener processes and products. UNEP/ SETAC Life Cycle Initiative, United Nations Environment Programme, Paris

Van der Voet E, Lifset R, Luo L (2010) Life-cycle assessment of biofuels, convergence and divergence. Biofuels 1(3):435-449

Wardenaar T, van Ruijven T, Mendoza Beltran A, Vad K, Guinéen J, Heijungs R (2012) Differences between LCA for analysis and LCA for policy: a case study on the consequences of allocation choices in bio-energy policies. Int J Life Cycle Assess 17(8):1059-1067

Weidema B (2000) Avoiding co-product allocation in life cycle assessment. Int J Life Cycle Assess 4(3):11-33

Weidema B (2014) Has ISO 14040/44 failed its role as a standard for life cycle assessment? J Ind Ecol 18:324-326

Weidema B, Schmidt J (2010) Avoiding allocation in life cycle assessment revisited. J Ind Ecol 14(2):192

Weidema B, Frees N, Nielsen A-M (1999) Marginal production technologies in life cycle inventories. Int J Life Cycle Assess 4:48-56

Weinzettel J (2012) Understanding who is responsible for pollution: what only the market can tell us - comment on "An ecological economic 
critique of the use of market information in life cycle assessment research.". J Ind Ecol 16(3):455-456

Werner F, Richter K (2000) Economic allocation in LCA — a case study about aluminium window frames. Int J Life Cycle Assess 5(2):79-83

WRI/WBCSD (2011) GHG Protocol - Product life cycle accounting and reporting standard. World Resources Institute (WRI) and World Business Council for Sustainable Development (WBCSD), USA
Zamagni S, Guinée J, Heijungs R, Masoni P, Raggi A (2012) Lights and shadows in consequential LCA. Int J Life Cycle Assess 17(7):904 918

Ziegler F, Winther U, Skontorp Hognes E, Emanuelsson A, Sund $\mathrm{V}$, Ellingsen $\mathrm{H}$ (2012) The carbon footprint of Norwegian seafood products on the global seafood market. J Indust Ecol 17(1):103-116 